\title{
A natureza jurídica pública dos serviços de saúde e o regime de complementaridade dos serviços privados à rede pública do Sistema Único de Saúde
}

Public legal nature of health services and the complementarity regime of private services to the Unified Health System

Lenir Santos ${ }^{1}$

RESUMO Análise do regime de complementaridade dos serviços privados ao Sistema Único de Saúde, mediante contrato ou convênio, e da natureza jurídica pública dos serviços de saúde. $\mathrm{O}$ regime de complementaridade dos serviços privados aos serviços públicos de saúde tem sido discutido de maneira bastante simplificada. Este estudo pretende fazer uma análise a respeito das características das ações e dos serviços de saúde, que decorrem do direito à saúde e à vida e contaminam sua execução, independentemente de sua titularidade pública ou privada. Além disso, o regime de complementaridade não configura nem fomento nem colaboração ao sentido da Lei ${ }^{0}$ 13.019, de 31 de julho de 2014.

PALAVRAS-CHAVE Cobertura de serviços privados de saúde; Cobertura de serviços públicos de saúde; Sistema Único de Saúde.

ABSTRACT Analysis of the complementarity regime of private services to Unified Health System, by contract or agreement and of the public legal nature of health services. The complementary system of private services to public health services has been discussed in a very simplified manner. This study aims to make a brief analysis about the characteristics of actions and health services that derive from the right to health and life and that contaminate its execution regardless of their public or private ownership. Besides, the complementarity regime does not configure neither promotion nor collaboration in the sense of Law 13.019, of July 31, 2014.

KEYWORDS Private health care coverage; State health care coverage; Unified Health System.

1 Instituto de Direito

Sanitário Aplicado (Idisa)

- Campinas (SP), Brasil.

Universidade Estadual

de Campinas (Unicamp),

Departamento de Saúde

Coletiva - Campinas (SP)

Brasil.

santoslenir@terra.com.br 


\section{Introdução}

Trata-se de análise do regime de complementaridade dos serviços privados ao Sistema Único de Saúde (SUS), mediante contrato ou convênio, conforme disposto no Art. 199, $61^{\circ}$, da Constituição Federal (CF) e no Art. 24 da Lei no 8.080 , de 19 de setembro de 1990 (BRASIL, 1988; BRASIL, 1990). O regime da complementaridade no âmbito do SUS não tem sido objeto de muitos estudos e debates, sendo necessário o seu aprofundamento, em especial ante à recente Lei $\mathrm{n}^{\circ} 13.019$, de 31 de julho de 2014, que trata do marco do terceiro setor (BRASIL, 2014).

$\mathrm{O}$ regime de complementaridade dos serviços privados aos serviços públicos de saúde tem sido discutido de maneira bastante simplificada, requerendo maior aprofundamento em razão da lei mencionada no parágrafo acima, que agora exigirá esforços no sentido de melhor situar a complementaridade na saúde pública, devido às características essenciais dos serviços de saúde, por decorrerem de direito fundamental, essencial à manutenção da vida e da garantia de sua dignidade.

Este estudo pretende fazer uma análise a respeito dessas características das ações e serviços de saúde, que decorrem do direito à saúde e à vida e que contaminam sua execução, independentemente de sua titularidade pública ou privada. A regulamentação das ações e serviços de saúde, que compete ao poder público, nos termos do Art. 197 da CF, não pode ignorar sua relevância como serviço que decorre de direito fundamental.

Releva notar ainda que o regime de complementaridade dos serviços privados à rede pública de saúde, nos termos do $\subseteq 1^{\circ}$ do Art. 199 da CF e do Art. 24 da Lei no 8.080/1990 (BRASIL, 1990), não configura nem fomento nem colaboração ao sentido da Lei $n^{\circ} 13.019 / 2014$, não incidindo sobre tal regime seus mandamentos legais. Por isso, até poderíamos entender que a previsão no Art. $3^{\circ}$, inciso II, da Lei ${ }^{0}$ 13.019/2014 (BRASIL, 2014), de que as suas disposições não se aplicam às 'transferências voluntárias' regidas por lei específica naquilo em que houver disposição expressa em contrário, alcançaria o regime da complementaridade do SUS estabelecido pela Lei ${ }^{\circ}$ 8.080/1990 (BRASIL, 1990). No entanto, a questão exige maiores reflexões pela necessidade de diferenciar a natureza das despesas realizadas no âmbito do SUS das modalidades de transferências de recursos existentes, sejam entre entes federativos, para pagamento de prestação de serviços ou para o fomento lato sensu. Tratei desse tema em recente artigo, que defende a não aplicabilidade da Lei $\mathrm{n}^{\circ}$ 13.019/2014, do qual o presente artigo é um desdobramento.

Por isso, é fundamental situarmos juridicamente o regime da complementaridade dos serviços privados ao SUS, na forma prevista na CF e na Lei no 8.080/1990 (BRASIL, 1990).

\section{Do Sistema Único de Saúde e o regime de complementaridade de sua rede de serviços}

A política de saúde e os serviços dela decorrentes são regidos pelos artigos 196 a $200 \mathrm{da}$ CF e por um conjunto de leis que lhes dão configuração técnico-administrativa bastante diferenciada dos demais setores públicos no tocante à sua organização e ao seu funcionamento. Seu principal marco legal é a Lei $\mathrm{n}^{\circ} 8.080 / 1990$, regulamentada pelo Decreto $\mathrm{n}^{\circ} 7.508$, de 28 de junho de 2011 (BRASIL, 1990).

Por determinação constitucional, o SUS é um sistema que integra ações e serviços públicos de saúde, em rede regionalizada e hierarquizada, o qual pode contar de forma complementar com os serviços privados de saúde, com ou sem fins lucrativos, com preferência para estes últimos (BRASIL, 1988, P. 41).

Art. 198. As ações e os serviços públicos de saúde integram uma rede regionalizada e 
hierarquizada e constituem um sistema único, organizado de acordo com as seguintes diretrizes: I - descentralização, com direção única em cada esfera de governo; II - atendimento integral, com prioridade para as atividades preventivas, sem prejuízo dos serviços assistenciais; III - participação da comunidade.

Art. 199. A assistência à saúde é livre à iniciativa privada. $\$ 10$. As instituições privadas poderão participar de forma complementar do sistema único de saúde, segundo diretrizes deste, mediante contrato de direito público ou convênio, tendo preferência as entidades filantrópicas e as sem fins lucrativos.

Primeiramente, o serviço público deve se estruturar em rede, em região de saúde, mediante a integração dos serviços dos entes federativos, sob o modelo técnico-sanitário de organização dos serviços de menor ao de maior complexidade tecnológica, com a atenção primária como porta principal e 'ordenadora' do sistema regional.

Nesse sentido, o serviço de atenção primária ou atenção básica (que, para nós, são sinônimos) não deve ser objeto de transferência ao setor privado no sentido de sua gestão indireta por organização social, por exemplo, tampouco complementado pelo setor privado (regime da complementaridade), por envolver poder de autoridade do Estado, em razão de ser o que ordena os demais, incumbindo-se das referências sanitárias e dos registros primários e permanentes da atenção à saúde, os quais devem conter a história de saúde do cidadão, sua trajetória no sistema de saúde, com todos os seus itinerários terapêuticos.

Em um segundo momento, a rede regionalizada pública poderá ser complementada por serviços do setor privado, sempre que o poder público verificar que suas disponibilidades são insuficientes, com preferência para as entidades sem finalidades lucrativas, excetuando-se a atenção primária, como dito acima.
Essa complementaridade, que permite ao poder público, em razão de sua insuficiência, garantir assistência à saúde à população mediante a conjugação de serviços de titularidade pública com os de titularidade privada, requer análise sobre a sua natureza, uma vez que essa complementação tanto poderá ser realizada por entidades privadas lucrativas como por entidades sem fins lucrativos, não havendo distinção entre elas no tocante ao objeto da prestação dos serviços. Ambas podem prestar os mesmos serviços, remunerados pelos mesmos valores, desde que os tenham e atendam aos requisitos técnicos impostos pela administração pública (BRASIL, 1990) e se submetam às suas diretrizes quanto ao seu funcionamento.

Lembremos, por oportuno, que 'saúde'1 é um termo polissêmico por comportar muitas variáveis, visíveis na própria definição da Organização Mundial da Saúde - "Saúde é um estado de completo bem-estar físico, mental e social, não consistindo somente na ausência de doenças ou enfermidade" (SANTOS, 2010, P. 28) -, que parece descrever o estado de felicidade, ao invés do de saúde, ou confundir ambos. Por isso, importa dizer que o SUS não compreende tudo o que a saúde pode significar, cabendo-lhe cuidar das ações e serviços de 'proteção, promoção e recuperação da saúde', o que já não é pouco e também requerer balizas e enquadramentos por ter custo.

A própria $\mathrm{CF}$, ao permitir que o setor privado nela atue, por não ser considerada como monopólio nem exclusividade pública, referiu-se à 'assistência à saúde' e não ao termo 'saúde' lato senso ${ }^{2}$. O setor privado não pode, por exemplo, atuar na proteção pública da saúde, atividade reservada à vigilância em saúde, privativa do poder público.

Os serviços do regime da complementaridade da rede SUS não estaria, ainda que de modo enviesado por não haver um bom enquadramento do serviço definido na Lei $\mathrm{n}^{\circ}$ 8.666, de 21 de junho de 1993 (BRASIL, 1993), com características próprias da

\footnotetext{
1 "A Constituição brasileira conferiu à saúde uma dimensão que vai além da biologia - uma dimensão biopolítica e social. [...] 0 direito à saúde, assim posto, exige que seja garantido ao cidadão viver em ambiente sadio, cabendo ao Estado à adoção de políticas sociais e econômicas que visem à redução das doenças, além de garantir acesso universal e igualitário às ações e serviços de saúde [...] responsabilidade do Sistema Único de Saúde [...]" (SANTOS, 2010, P. 25).

2 Pelo fato de os serviços de saúde terem características próprias organizativas, como rede, região, hierarquização de serviços, direção única em cada esfera de governo, a Lei de Licitação e Contratos deve ser aplicada respeitando-se essas especificidades.
} 
${ }^{3}$ Assegurado pelo Estado, tanto em seu sentido lato de garantia de qualidade de vida como no sentido estrito de garantia de serviços que protejam e recuperem a saúde, permitindo, ainda, à iniciativa privada atuação no campo da recuperação da saúde, sob controle público, até mesmo para a salvaguarda do direito em razão da essencialidade. saúde, Possui multifacetas, como remuneração pré-estabelecida em tabela; sujeição aos regulamentos do SUS; e integração ao SUS organizado em níveis de complexidade crescente, que compõem uma rede regional de saúde, sujeitando-se aos referenciamentos do próprio sistema e a outras normas. Imagine-se pensar a rede SUS como projeto básico, projeto executivo, técnica e preço, escolha de melhor proposta etc.

Esse é um tema caro ao SUS, que, até o presente momento, não foi equacionado adequadamente, pendente ainda na formalização de muitos contratos entre entes públicos e o setor privado e em como devem ser feitas as escolhas dentro dos princípios da administração pública. Sempre defendi que, na maioria das vezes, a inexigibilidade de licitações está presente pelas características próprias da saúde, como a organização dos serviços em rede, que requer, na maioria das vezes, chamamento para 'negociação entre todos os interessados em participar do SUS complementarmente'. A inexigibilidade é muito mais presente do que se pode pensar, na área da saúde.

Di Pietro (2006) entende que esses contratos de complementaridade de serviços se encaixariam no conceito dos serviços regulamentados pela Lei de Licitação e Contratos ${ }^{3}$, mesmo quando a entidade fosse sem fins lucrativos, desde que houvesse prestação de serviços e remuneração, defendendo, ainda, a existência, presentes seus pressupostos, da parceria no âmbito do SUS, quando o convênio seria a modalidade jurídica adequada.

Como a 'complementaridade' do serviço no SUS não traz em si distinção entre ser, o mesmo, 'lucrativo ou não', importa a discussão, a ser travada mais adiante, sobre a 'preferência' de participar dessa rede garantida às entidades sem fins lucrativos.

O Art. $4^{\circ}$ da Lei no 8.080/1990 (BRASIL, 1990), bem como o Art. 24, reforça o entendimento de que a complementaridade de serviços é um regime diferenciado do regime de parceria e fomento, conforme vimos acima no tocante ao seu elemento orçamentário.
A complementaridade na Lei $n^{\circ}$ 8.080/1990 está definida no $\subseteq 2^{\circ}$ do Art. $4^{\circ}$ :

Art. 4․ O conjunto de ações e serviços de saúde, prestados por órgãos e instituições públicas, estaduais e municipais, da Administração direta e indireta e das fundações mantidas pelo Poder Público, constitui o Sistema Único de Saúde (SUS). [...] § 2‥ A iniciativa privada poderá participar do Sistema Único de Saúde, em caráter complementar. (BRASIL, 1990).

As normas sobre a participação complementar - o Capítulo II da Lei no 8.080/1990 demandaria regulamentação para elucidar dúvidas que sempre permaneceram nessa relação, em especial a questão da preferência das entidades sem fins lucrativos, bem como a própria licitação nem sempre viável, posto que, na maioria das vezes, cabe a declaração de inexigibilidade de licitar em razão das características organizativas do SUS - determinam que, quando as disponibilidades públicas forem insuficientes para garantir a cobertura assistencial à população de uma determinada área, o SUS poderá recorrer aos serviços 'ofertados' pela iniciativa privada, devendo formalizar a relação jurídica, mediante 'contrato ou convênio', observadas as normas de direito público.

Dispõe, ainda, em respeito à determinação constitucional, que as entidades filantrópicas e as sem fins lucrativos terão preferência para participar do SUS (Art. 25) (BRASIL, 1990). Defendi, durante muito tempo, que a 'preferência' imporia um regime de parceria entre o poder público e a entidade filantrópica, mas após novas reflexões a respeito do tema, entendo que a complementação dos serviços privados de saúde à rede pública de saúde tem um regime próprio. Seriam necessários regramentos sobre essa complementaridade, tendo em vista tratar-se de uma rede pública de saúde, integrada pelo setor privado lucrativo ou não, os quais se sujeitam a regras próprias de contratação, nunca reguladas (CARVALHO; SANTOS, 2004). 
É importante destacar que o prestador do serviço privado, em especial hospitais e laboratórios, na grande maioria das vezes, sempre contratualiza com o SUS 'parte' de seus serviços, coexistido no mesmo serviço, parcela de atendimento ao SUS, sujeita às suas diretrizes, e parcela sujeita aos regramentos do próprio prestador.

Há os que defendem, contrariamente ao meu entendimento, que, na participação complementar há 'delegação', conforme ocorre com os serviços exclusivos. Soaria bastante estranha essa delegação, 'para serviços que já existem sem delegação' e que podem continuar existindo após o término do contrato com o poder público, além do fato de o contrato ter como objeto, geralmente, apenas 'parte' do serviço existente da entidade. Para uma parte do serviço haveria delegação e para a outra não. A delegação não pode apenas se referir à possibilidade de a entidade prestar os seus serviços (já existentes) aos usuários do SUS, mediante contrato. A delegação, nesse caso, seria para participar do SUS, o que não é uma delegação por não haver outorga, traspasse de competência nessa relação contratual, mas tão somente a possibilidade de utilização de um serviço privado pelo usuário do SUS, sujeito às suas diretrizes. Encerrado o contrato, o serviço continuará existindo normalmente (MÂNICA, 2010).

Essas avenças abrangem indistintamente o setor privado lucrativo e o sem fins lucrativos. Não há diferenciação dos serviços complementares de saúde prestados por entidades com finalidades lucrativas e por entidades sem finalidades lucrativas em seu sentido lato. Ambas complementam igualmente a rede pública de saúde mediante prestação de serviços de assistência à saúde. São os mesmos serviços previstos em tabela de procedimentos diagnósticos, ambulatoriais, médicos, terapêuticos e hospitalares.

Os artigos 24 a 26 da Lei ${ }^{\circ} 8.080 / 1990$ tratam do tema no Capítulo II, referente à participação complementar.
Art. 24. Quando as suas disponibilidades forem insuficientes para garantir a cobertura assistencial à população de uma determinada área, o Sistema Único de Saúde (SUS) poderá recorrer aos serviços ofertados pela iniciativa privada.

Parágrafo único. A participação complementar dos serviços privados será formalizada mediante contrato ou convênio, observadas, a respeito, as normas de direito público.

Art. 25. Na hipótese do artigo anterior, as entidades filantrópicas e as sem fins lucrativos terão preferência para participar do Sistema Único de Saúde (SUS).

Art. 26. Os critérios e valores para a remuneração de serviços e os parâmetros de cobertura assistencial serão estabelecidos pela direção nacional do Sistema Único de Saúde (SUS), aprovados no Conselho Nacional de Saúde.

§ $1^{\circ} \mathrm{Na}$ fixação dos critérios, valores, formas de reajuste e de pagamento da remuneração aludida neste artigo, a direção nacional do Sistema Único de Saúde (SUS) deverá fundamentar seu ato em demonstrativo econômico-financeiro que garanta a efetiva qualidade de execução dos serviços contratados.

$\S 2^{\circ}$ Os serviços contratados submeter-se-ão às normas técnicas e administrativas e aos princípios e diretrizes do Sistema Único de Saúde (SUS), mantido o equilíbrio econômico e financeiro do contrato. (BRASIL, 1990).

O fundamento principal da complementaridade está na 'insuficiência' dos serviços públicos para a garantia da assistência à saúde ao cidadão de uma determinada área e, como consequência, na existência desses serviços no setor privado. Havendo comprovada insuficiência, a rede pública poderá ser complementada pelos serviços privados, que passarão a integrá-la nos limites de sua insuficiência, com preferência na contratação dos serviços das entidades sem finalidades lucrativas. Isso 
significa dizer que a instituição privada irá prestar os seus serviços nas suas próprias instalações, observadas as diretrizes do SUS.

Os critérios e valores de remuneração são definidos pela direção nacional do SUS e aprovados no Conselho Nacional de Saúde, sem distinção de remuneração para serviço privado lucrativo ou sem fins lucrativos. Ambos se sujeitam ao que usualmente se denomina tabela de procedimentos do SUS.

Não se confunde com a concessão de serviços públicos (Art. 175 da $\mathrm{CF}$ ), que não se destina a complementar uma 'rede de serviços já existente'. Na concessão, o serviço público depende de delegação; é remunerado diretamente pelo usuário por taxa (tarifa ou preço público); sua organização é atribuição exclusiva do delegatário (concessionário), que o faz às suas expensas (BRASIL, 1988).

Como traço distintivo, temos que a saúde não é exclusiva, não depende de delegação para o serviço existir (e continuar a existir se o contrato com o poder público se encerrar), não tem tarifa e pode 'complementar' uma rede de serviço público 'existente'. Contudo, os serviços públicos exclusivos e seu regime de concessão, e os serviços de saúde e seu regime da complementaridade têm um traço em comum: sua natureza pública. Ambos são serviços públicos em essência, independentemente de sua titularidade ser pública ou privada, por delegação (Art. 175 da CF) ou por prévia autorização constitucional (Art. 199 da $\mathrm{CF}$ ), integrando ou não a rede SUS, conforme veremos em outro tópico (BRASIL, 1988).

Não concordo com as defesas de que haveria delegação de competência na participação complementar do setor privado no SUS (MÂNICA, 2010). Se fosse necessária essa delegação, os serviços não poderiam existir por si sós, antes de complementarem a rede pública; e se não existissem, não poderiam integrá-la. A sua existência (Art. 199, $\S 1^{\circ}$ ) (BRASIL, 1988) não configura outorga, não sendo uma delegação por não haver transferência ao particular de poderes e prerrogativas públicas (DI PIETRO, 2006); a entidade privada executa o serviço em nome próprio e a integração ao SUS é uma faculdade: pode ou não acontecer, mas o serviço existirá, independentemente.

A complementaridade foi uma necessidade, uma vez que o SUS, criado em 1988, não contava com serviços públicos suficientes. A previsão constitucional se fundamentou na realidade fática: $70 \%$ dos serviços de saúde do Inamps eram privados, complementares, que se inseriam na rede da autarquia mediante credenciamento universal. Fatalmente, teria o SUS que contar com os serviços privados 'que já complementavam' os serviços prestados pelo Inamps aos seus beneficiários. (Participei das discussões da Reforma Sanitária, bem como das discussões e da elaboração da Lei ${ }^{\circ} 8.080 / 1990$, e o sentido da complementaridade era a realidade fática, tanto quanto o da preferência das entidades filantrópicas, por serem a grande maioria. Além disso, ainda havia a importância de se privilegiar quem atuava em prol do interesse público).

Os critérios e valores para a remuneração de serviços e os parâmetros de cobertura assistencial já eram definidos pelo Inamps em tabela, e assim continuaram, com modificação ao longo do tempo. O SUS manteve, no início, o mesmo procedimento de pagamento e foi garantido, na lei, que seus preços fundar-se-iam em demonstrativo econômico-financeiro - em razão da alta inflação da época -, de garantia da qualidade, submetendo-se às normas técnicas e administrativas e aos princípios e diretrizes do próprio SUS, sendo mantido, ainda, o equilíbrio econômico-financeiro do contrato.

São elementos do regime de complementaridade, conforme a Lei ${ }^{0}$ 8.080/1990:

a) insuficiência de serviços públicos;

b) existência de serviços privados;

c) pagamento fundado em tabela de preço; 
d) celebração de contrato ou convênio, com preferência para as entidades sem fins lucrativos;

e) observância das diretrizes do SUS.

No caso de não haver, em determinada localidade, serviço privado para complementar o público, poderá ser estabelecido algum tipo de parceria, se o poder público entender ser essa a melhor solução, para a sua instalação de serviços com fomento público. Nesse caso, ainda que a rede pública venha a ser complementada pelo setor privado, teremos que analisar se o que irá prevalecer será o fomento, a parceria público-privada da Lei ${ }^{\circ} 11.079$, de 30 de dezembro de 2004, ou o regime de complementaridade com prestação de serviços remunerados por tabela e afins, para definir a incidência de qual regime jurídico irá reger as mútuas relações (BRASIL, 2004).

Nesse modelo, se sobressai a característica de 'ausência' de serviço público, que passa a ser complementado pelo serviço privado, mediante remuneração previamente fixada.

É claro que existem outras formas de atuação do Estado, que contam com a participação do setor privado, como ocorre com as organizações sociais e demais modelos legais vigentes. Ainda que lato sensu, esses modelos também integrem a rede de serviços públicos e não podem ser considerados como serviços 'complementares', stricto sensu, nos termos do disposto na CF e na Lei no 8.080/1990, em razão de a lei ter fundado essa complementaridade na "ausência de serviços públicos necessários ao atendimento da população e existência de instituições privadas que podem fornecê-los".

Vejamos o caso da Associação das Pioneiras Sociais: os serviços eram públicos; já existiam e passaram a ser geridos por uma associação privada por força de lei; os hospitais paulistas construídos e equipados foram objeto dos contratos de gestão com as organizações sociais regidas por lei específica estadual, a Lei Complementar n ${ }^{\circ}$ 846, de 04 de junho de 1998 (SÃO PAULO, 1998).

Abrindo parênteses, não cabe aqui falar em contratação de atividade-meio e atividade-fim por não se tratar de contratação de terceiro para atuar no próprio serviço público (polêmica até hoje não sanada em razão do concurso público, fato que pôs fim, depois de muitos e muitos anos, ao 'Código 7’4, que era exatamente a contratação dos médicos apartados do contrato de complementaridade), mas sim de complementação de serviço público com serviço de instituições privadas já existentes (\$ $1^{\circ}$ do Art. 199) (BRASIL, 1988).

Em um caso, o serviço público é complementado por serviços 'externos privados', mediante pagamento de procedimentos. Em outro, o poder público fomenta a prestação de serviços públicos por terceiros (privados), mediante o cumprimento de metas de desempenho, podendo envolver a cessão de imóveis e bens públicos existentes ou que estão em organização, muitas vezes em esquema de 'quase cogestão'.

Uma categoria não suprime a outra. Ambas coexistem, mas devem ser analisadas à luz de suas peculiaridades e à da legislação que as ordenam. A primeira se sujeita à Lei de Licitação e Contratos, com suas dispensas e inexigibilidade, e a segunda, às leis que regulam o fomento e a colaboração de forma ampla. Como já vimos, as despesas realizadas na primeira são enquadradas orçamentariamente como compra de serviços de pessoas jurídicas (modalidade de aplicação 90) e a segunda como parceria e fomento (modalidade de aplicação 50).

À evidência de que a complementaridade do $\subseteq 1^{\circ}$ do Art. 199 da CF não suprime as parcerias entre o poder público e o setor privado (fomento e colaboração) - até mesmo porque ela própria não é uma parceria stricto sensu -, as parcerias devem ser estudadas sob a ótica das relações de fomento e colaboração tratadas em outras leis, como a Lei $\mathrm{n}^{\circ}$ 9.637, de 15 de maio de 1998 (Organizações Sociais); a Lei $\mathrm{n}^{\circ} 9.790$, de 23 de março de

\footnotetext{
4 O Código 7 se referia à forma de pagamento dos médicos. Nos contratos com o setor privado, o Inamps contratava a pessoa jurídica, hospital, e a pessoa física, médico em separado do hospital, o que ensejou inúmeras ações judiciais para declarar vínculo de trabalho entre a pessoa física e o Inamps.
} 
1999 (Organizações da Sociedade Civil de Interesse Público); a Lei $\mathrm{n}^{\circ}$ 8.246, de 22 de outubro de 1991 (Pioneiras Sociais); e a Lei $\mathrm{n}^{\mathrm{o}}$ 13.019, de 31 de julho de 2014 (Parcerias Voluntárias).

Tem sido usual firmar contrato para ajustar a relação obrigacional com a entidade lucrativa e o convênio com as sem fins lucrativos. O que tem fundamentado de forma equivocada essa escolha não é o 'objeto' da relação jurídica, mas sim a 'finalidade' da entidade: se lucrativa, o contrato; se sem fins lucrativos, o convênio. Ainda que o objeto seja sempre o mesmo - prestação de serviço que falta no serviço público e precisa ser complementado -, é comum essa interpretação.

Até o presente momento, essa escolha está ao sabor da praxe administrativa: o contrato deve ser firmado com a entidade que visa lucro e o convênio com a entidade que não o visa. Uma visão equivocada e antiquada: no meu entendimento, o contrato seria a forma correta de ajuste para a complementaridade, mesmo tendo as entidades sem finalidades lucrativas preferência; bastaria regulá-la. Havendo insuficiência, primeiro se recorre ao setor sem fins lucrativos e depois ao setor lucrativo.

O fundamento da escolha não deve ser a 'finalidade' da entidade e sim o 'objeto' do ajuste, que é o de prestação de serviços de saúde complementares aos serviços públicos na rede interfederativa de saúde. A preferência da entidade filantrópica precisa ser disciplinada para uma melhor compreensão do regime da complementaridade, a qual deve se assentar na relevância e na natureza pública do serviço de saúde, que confere ao poder público competência para intervir na saúde, podendo até mesmo requisitar serviços quando necessário.

O Art. 197 da CF dispõe sobre os serviços públicos e privados (BRASIL, 1988). Por isso, determina que os mesmos podem ser executados 'diretamente' pelo poder público ou 'através de terceiros'; e por pessoas físicas (médicos, terapeutas, dentistas) ou jurídicas (hospitais, laboratórios, clínicas) de direito privado.

A relação jurídica deve se estabelecer pelo contrato de prestação de serviços complementares de saúde, independentemente de a entidade ser com ou sem fins lucrativos. Além do mais, conforme veremos abaixo, são muitas as especificidades da saúde que devem ser consideradas nessa relação contratual, tais como: a direção única em cada esfera de governo; o fracionamento do serviço para se construir rede de serviços; uma delimitação de território para a prestação dos serviços; e a inexigibilidade de licitar como fato frequente, entre outras.

\section{A preferência das entidades filantrópicas e sem fins lucrativos na participação complementar ao SUS}

A preferência garantida ao setor privado sem fins lucrativos é histórica na saúde, o que remonta ao papel das santas casas e demais serviços religiosos que atuavam na área da saúde de modo desinteressado desde o Império.

Considerando que somente nas décadas de 1920-1930 os trabalhadores formais passaram a fazer parte do sistema de previdência social (com os institutos de seguro social), o qual incluía os serviços médicos e hospitalares entre os benefícios previdenciários, as santas casas desempenharam relevante papel de garantia de serviços de saúde às pessoas afastadas da previdência pública - que ficavam ao sabor da assistência caritativa púbica ou privada - ao mesmo tempo em que mantinham relações de parceria com os poderes públicos para complementar serviços do Inamps, mediante pagamento, auxílios, subvenções públicas.

O próprio Inamps mantinha, com as santas casas e demais serviços sem fins lucrativos, uma relação diferenciada no tocante à sua 
contratação. Como os serviços públicos de saúde previdenciários não eram suficientes para a garantia das necessidades dos trabalhadores, esses serviços eram essenciais e a formalização dessa parceria se dava tanto pelo credenciamento de serviços e de profissionais de saúde (o famoso Código 7).

Nos debates na Assembleia Nacional Constituinte seria impossível discutir saúde sem considerar os serviços das santas casas ou das entidades filantrópicas. Nasceu, assim, a necessidade de se manter a sua preferência, já considerada anteriormente de modo informal. Até porque grande parte dos serviços complementares aos do Inamps eram de entidades filantrópicas, com poucos serviços lucrativos possuindo relação contratual com o poder público.

A própria imunidade fiscal das entidades sem fins lucrativos nem sempre lhes gera superávit, tendo em vista as dificuldades em relação ao seu financiamento, pelo fato de serem obrigadas a prestar $60 \%$ de seus serviços ao SUS, entre outros motivos.

A não regulamentação da preferência das entidades sem fins lucrativos é um ponto de dificuldade. Recentemente, tribunais de contas como o do Estado de São Paulo, ao analisarem os convênios firmados para a complementaridade dos serviços, os veem como de parceria, e nunca como contratos de prestação de serviços, remunerados por tabela de preço, semelhantes em tudo aos contratos celebrados com as entidades lucrativas.

Esse entendimento tem sido polêmico ante a ingerência do poder público na gestão dessas entidades, com imposição de rotinas administrativas e até mesmo de restrição quanto à aplicação dos recursos em determinadas atividades em decorrência do convênio, interferindo na sua forma de atuação privada. $O$ poder público tem grande capacidade de interferência no setor privado, tanto quanto no público.

Apenas para lembrar, o Art. $5^{\circ}$, XVIII, da CF veda a intervenção pública na estrutura e no funcionamento das entidades privadas, e a Emenda Constitucional $n^{\circ} 29$, de 13 de setembro de 2000 , permite a intervenção da União no Estado quando o mesmo não cumpre com sua obrigação de aplicar $12 \%$ de suas receitas na saúde, o mesmo ocorrendo em relação ao Estado-membro, quanto aos seus municípios (BRASIL, 1988).

Havendo subvenção, auxílio, concessão de bem público, o contrato deverá fazer menção aos ajustes específicos necessários, nos termos da legislação do ente público. O que deve orientar a avença deve ser o seu 'objeto' e não o fato de a entidade ser ou não lucrativa. Se o objeto não é fomento nem colaboração, a categoria jurídica que mais se ajusta é a do contrato.

\section{A natureza jurídica dos serviços de saúde}

É importante refletir, ainda que muito brevemente, sobre as consequências de a rede pública ser integrada por serviços privados, os quais a complementam nas prestações públicas. Nessa linha, cabe perquirir sobre a 'natureza jurídica' dos serviços de saúde (públicos ou privados), em relação aos efeitos que podem produzir no dever estatal de garantia de saúde, na própria interpretação de normas de direito privado aplicáveis aos serviços privados, como, por exemplo, no de controle de preços (BRASIL, 1993), dos planos de saúde, das cláusulas contratuais de prazo de internação etc.

Se não houver uma mesma natureza pública que irradie seus valores sobre os serviços de saúde, independentemente de sua titularidade, e confira ao poder público amplos poderes de intervenção e ao cidadão, de reivindicação de maiores cautelas na sua prestação, poderíamos ter um mesmo direito fundamental protegido de forma distinta quando distintos forem seus titulares. Se assim fosse, a saúde não seria um direito fundamental quando prestada pelo particular. $\mathrm{E}$ como poderia, ainda, a rede pública de saúde ser complementada pelo serviço privado? 
Tratando-se de um direito fundamental consagrado no Art. $6^{\circ}$ da CF, definido como direito social que tem como objetivo o bem-estar e a justiça social (Art. 193), inserido na seguridade social (artigos 194 a 200) como um direito a prestações públicas, a natureza jurídica do serviço deve ser uma só para a proteção do cidadão, uma vez que a sua titularidade não é exclusivamente pública (BRASIL, 1988).

A redação do Art. 197 da CF deixa claras quatro questões que nos levam a considerar a sua natureza pública (BRASIL, 1988):

1. Os serviços de saúde públicos ou privados são de relevância pública;

2. Os serviços de saúde públicos ou privados estão inteiramente sob regulamentação, fiscalização e controle público;

3. Os serviços 'públicos' devem ser executados diretamente ou através de terceiros; e

4. Os serviços 'privados' podem ser executados por pessoas jurídicas ou físicas.

A criação da Agência Nacional de Saúde (ANS), reguladora do seguro e dos planos de saúde, ainda que não se trate de serviço público 'exclusivo' - que pode ser delegado -, reforça o entendimento de que o serviço, em sua essência, mesmo quando tem titularidade privada, é de natureza pública e deve estar inteiramente sob regulação, fiscalização e controle púbico. Por isso na Assembleia Nacional Constituinte esse tema foi objeto de intensos debates.

Há, ainda, que se fazer essa distinção no Art. 197 ao se tratar de ambos os serviços: de titularidade pública e de titularidade privada. Em um momento, a CF se refere ao serviço público; em outro, ao serviço privado.

As características da saúde e o papel que o poder público desempenha na garantia de prestações de proteção, promoção e recuperação, e no dever de regular, fiscalizar e controlar todas as suas atividades - sejam públicas ou privadas - demonstra o reconhecimento de sua essencialidade, garantindo-lhe natureza pública, independentemente de sua titularidade.

É sua natureza pública que permite a complementaridade do sistema público por serviços privados, mesmo sendo os mesmos lucrativos. Trata-se de uma mesma natureza para um mesmo serviço, independentemente de sua titularidade, por não ser este o seu traço distintivo, mas sim a sua 'fundamentalidade e relevância pública'. Para Eros Roberto Grau (1992), todos os serviços públicos são de relevância pública, podendo, ainda, alguns serviços privados também o serem. Para Ferraz e Benjamim (1992), a essencialidade do serviço mantém no Estado um poder de intervenção em nível mais elevado do que em relação a outros serviços prestados por particulares.

O mesmo pode-se dizer dos serviços exclusivos do Estado (Art. 175 da CF). Eles podem ter titularidade privada, por delegação, exatamente por sua natureza ser pública e isso contaminar a sua prestação privada, sujeita ao controle público, garantido maior poder de intervenção pública e maior poder de reivindicação ao particular.

É importante considerar que o Art. 197 da CF trata dos serviços de saúde, públicos e privados. Por isso, referiu-se a eles como de relevância pública, por estarem os serviços privados compreendidos naquela norma, garantindo a todos, sem distinção, mesma natureza pública, conforme debate da Assembleia Nacional Constituinte.

Não poderia a rede pública de saúde ser composta por serviços privados 'destituídos' do peso da sua fundamentalidade, como se fossem um serviço de mero consumo e comércio, sem nenhuma consequência que não a sua proteção no campo dessas relações comerciais. Seria um contrassenso compor um sistema público com um serviço de titularidade privada, se esse serviço não fosse, em sua 'jusgenética', público. Há serviços 
privados que, pela sua essencialidade ou pela sua fundamentalidade, não podem tão somente estar sob a proteção do consumo.

Esse debate foi travado mais recentemente no Supremo Tribunal Federal (STF), com os ministros Joaquim Barbosa e Eros Roberto Grau (ADI $1266-5^{5}$ e 1007-76) defendendo a saúde (e a educação) como sendo serviços públicos em sua genética, independentemente de sua titularidade, não sendo a titularidade executiva o que caracterizaria a natureza do serviço, demarcada pela $\mathrm{CF}$ como direito fundamental, dever do Estado e de relevância pública.

Pode-se afirmar que, em sede de direito fundamental, a natureza pública do serviço é consequência. Não se pode comparar a atividade de saúde, considerada na CF como direito fundamental e dever do Estado, com as demais atividades que não o são. A própria autorização constitucional (Art. 199, caput) para a iniciativa privada atuar na assistência à saúde é decorrência dessa natureza.

Mello (2002) refere-se a quatro hipóteses de tratamento dado pela CF aos serviços públicos: a) os serviços de prestação obrigatória e exclusiva do Estado; b) os serviços de prestação obrigatória do Estado e em que é obrigatória a outorga em concessão a terceiros; c) os serviços de prestação obrigatória pelo Estado, mas sem exclusividade (a saúde, por exemplo); d) o serviço de prestação não obrigatória pelo Estado.

A CF precisou autorizar a iniciativa privada a atuar na assistência à saúde. Fosse um serviço de outra categoria, seria livre por força do Art. 170 (Livre Iniciativa), tão somente. Por se tratar de um serviço de natureza pública, foi necessário o legislador afirmar que o serviço de assistência à saúde, que é público por natureza, não era privativo quanto à sua execução (BRASIL, 1988). Não fosse a expressa autorização, a saúde seria de exclusividade pública.

A fundamentalidade desse direito é que leva à legitimação da atuação do Estado, no sentido de disciplinar essa prestação (ADI 1266,
DE 2005). É a natureza pública do serviço que permite que seja o sistema público de saúde complementado por serviço de titularidade privada e sujeito a maior poder de intervenção do que aqueles próprios das relações de consumo. Não seria cabível a saúde ter o mesmo tratamento, igualando-se à compra de sapatos ou aos serviços de limpeza, em sua relação com o prestador do serviço.

O mesmo debate foi travado pelos mesmos Ministros do STF, na ADI 1007-7, de 2005, na discussão do direito à educação, tendo o Ministro Eros Grau, relator, defendido que se a Constituição diz que a educação e a saúde são livres, é exatamente porque elas são livres e independem de concessão ou permissão, embora sejam serviços públicos. Acrescentaria que eles são de natureza pública e dever estatal, com autorização constitucional para o setor privado nelas atuar.

Paulo Modesto (2011, P. 36) expõe que, na aplicação do direito público às entidades privadas sem fins lucrativos, mesmo os autores que

dilatam a aplicação do conceito de serviço público para atividades sem titularidade do Estado reconhecem que, quando os particulares atuam, com ou sem fins lucrativos, por direito próprio (iure proprio), não se sujeitam ordinariamente ao regime do serviço público ou do direito administrativo, mas ao regime jurídico típico ou predominante das pessoas de direito privado, ou que muitas vezes lhe confere maior agilidade ou presteza no atendimento dos seus objetivos sociais.

A relação do cidadão com o serviço de saúde é de direito, ainda que possa ser explorado economicamente e haja preço e lucro. Não é o prestador que qualifica o serviço, mas sim a sua a fundamentalidade, a sua proteção pública, o seu valor, sua genética de direito vinculado à vida. Seria bastante redutor e perigoso classificar o serviço público tão somente pela sua titularidade, tendo em vista o aprofundamento, no mundo

\footnotetext{
5 Disponível em:

$<$ http://www.stf.jus.

br/portal/processo/ verProcessoAndamento. asp? incidente $=1613347>$.

6 Disponível em: <http://www.stf.jus. br/portal/processo/ verProcessoAndamento. asp?incidente $=1580199>$.
} 
de hoje, das relações de parceria público-privada, de complementaridade privada ao público. Importante é o valor que a $\mathrm{CF}$ garante ao serviço público, mesmo quando é permitida a sua execução a terceiros; são as consequências desse valor para o cidadão e para o controle público e social.

A dimensão de direito fundamental da saúde tem sido reconhecida pelos tribunais nos julgamentos de conflitos de planos privados, os quais se sujeitam à regulação de uma agência própria (BRASIL, 1998), sem, contudo, ser serviço público exclusivo, no qual a atuação do particular se dá por delegação. A saúde não é serviço público exclusivo, mas é serviço de natureza pública, fundamento para se criar uma agência reguladora sem que ela seja serviço exclusivo, sede principal de atuação das agências reguladoras.

Por isso, o serviço de saúde privado não pode ser protegido apenas em sua relação de consumo. Essas importantes características prestacionais da saúde a qualificaram como serviço de relevância pública, no Art. 197 da CF (BRASIL, 1988).

Na Assembleia Nacional Constituinte, esse debate foi acirrado exatamente porque se preconizava a natureza pública das ações e dos serviços de saúde, públicos e privados. A redação do Art. 197 originalmente (com numerações diferentes em suas várias versões) mencionava a natureza pública dos serviços de saúde. Algumas redações: 'As ações de saúde são funções de natureza pública, cabendo ao Estado a sua normatização, execução e controle'; 'As ações de saúde são de natureza pública, cabendo ao Estado sua regulamentação, execução e controle'; 'As ações e serviços de saúde são de natureza pública' (BRASIL, 1988). O debate encerrou-se com o acordo entre os constituintes do bloco denominado 'Centrão' e os de esquerda, para considerar os serviços de saúde como de 'relevância pública'. O receio era de que a 'natureza pública' pudesse ser interpretada como serviço de 'exclusividade' pública, dependente de delegação e não em razão da fundamentalidade do direito. Essa foi a razão da mudança, que levou, na época, alguns especialistas e juristas - como Dalmo Dallari - a se pronunciarem a respeito nos Anais da Assembleia Nacional Constituinte e em documentos impressos do acervo da Biblioteca do Instituto de Direito Sanitário Aplicado (Idisa), além de em eventos presenciados por esta autora.

Aliás, devemos lembrar, ainda, que o poder público, na área da saúde, pode requisitar serviços quando estes forem necessários para a garantia de direitos (Art. 15, XIII, Lei $n^{\circ} 8.080 / 1990$ ) (BRASIL, 1990). A saúde pode ser explorada economicamente, mas não é um comércio no sentido literal da palavra. O poder público deve ser seu vigilante permanente, formulando políticas públicas que impliquem o setor privado e tendo poder de intervenção sempre que necessário. Bens protegidos constitucionalmente, quando explorados economicamente ficam ao resguardo público; para a sua proteção, há um guardião de suas relações.

A natureza jurídica pública da saúde é alicerce nas negociações, não oferecendo assim risco ao equilíbrio nos consensos futuros. Por isso, não importa quem exerce a sua titularidade (o poder público ou o setor privado); tampouco isso deve contaminar a sua 'forma de execução', que seguirá os cânones do direito administrativo se a titularidade for pública, e os do direito privado se a titularidade por privada. Serviços públicos 'exclusivos' e serviços públicos 'fundamentais de natureza não exclusiva' têm a mesma natureza pública, o que permite sua execução direta ou indireta, dado o poder de resguardo público sobre suas ações.

\section{Conclusões}

De tudo que vimos acima, uma conclusão irrefutável: 'a participação complementar do setor privado no Sistema Único de Saúde’ tem especificidades próprias, que não permitem 
o seu enquadramento nas regras da Lei $\mathrm{n}^{\mathrm{o}}$ 13.019/2014, por não se tratar, stricto senso, nem de parceria nem de fomento.

$\mathrm{O}$ regime jurídico da complementaridade do SUS pelo setor privado não encontra fundamento nem na definição do fomento nem na de colaboração do Art. $2^{\circ}$, VI e VII da mencionada lei.

1. A 'complementaridade' do SUS por serviços privados, lucrativos ou não, configura um regime diferenciado da relação público-privada, o qual demanda regulação e melhor definição jurídica, enquadrando-se como prestação de serviço de natureza pública e não como parceria (colaboração e fomento). Isso não significa que não possa haver, na saúde (aliás, onde é sobejante), relações de fomento e parceria, como a das Organizações Sociais (OS), Organizações da Sociedade Civil de Interesse Público (Oscip) e outras. Contudo, as referentes à complementaridade prevista na CF, Art. 199, $\subseteq 1^{\circ}$, e nos artigos 24 a 26 da Lei no $8.080 / 1990$, não podem assim ser enquadradas.

2. Abaixo, um resumo de elementos próprios do regime de complementaridade dos serviços de saúde:

3. A complementaridade de serviços, mediante contrato ou convênio, não pode ser definida como parceria ou fomento. A complementaridade é uma forma de suprir o SUS de serviços que lhe faltam, não podendo se falar em programa aprazado, mas sim em integração de serviços privados num sistema de grande complexidade organizativa, prestado de forma contínua, o qual onera modalidade orçamentária relativa à aquisição de serviços (modalidade 90) e elemento de despesa próprio de pagamento de serviços técnicos de terceiros (39).
4. Nem sempre a disputa (licitação) entre serviços complementares é necessária porque o poder público, na maioria das vezes, não deve contratar a totalidade dos serviços de uma única entidade, em razão da organização dos serviços em 'rede', que exige fracionamento, além de não haver disputa de preço.

5. Os serviços devem ser adquiridos em territórios demarcados - região de saúde -, não sendo passíveis de chamamento público nacional.

6. Os prazos dos contratos ou convênios têm caráter mais longo pelo fato de tratarem de serviços continuados e não de programas ou fomento de atividades com prazo certo. Na maioria das vezes - mais de $80 \%$, só existe uma santa casa no município e esse serviço é permanente.

7. O serviço contratado pode ser complementado com equipamentos e bens públicos necessários aos serviços, conforme ajuste no contrato e compensação financeira; outras vezes, a entidade contratada privada necessita comprar equipamento oneroso e não pode ficar sujeita a contrato de pequeno prazo de duração, como é o caso, por exemplo, da hemodiálise. O regime da complementaridade tem especificidades próprias da rede SUS.

8. A direção única em cada esfera de governo - de acordo com as pactuações intergestores - não permite que um município adquira serviço de outro município. Essa questão se vincula às referências sanitárias vinculadas à região de saúde e às definições nas comissões intergestores.

9. Os chamamentos públicos na saúde devem resguardar as suas 
especificidades: rede, preço fixo, territorialidade dos serviços em relação à população. Trata-se, na maioria das vezes, muito mais de uma negociação coletiva para complementar uma rede pública do que uma disputa de proposta e preço de serviços com apenas um vencedor.

10. As definições das necessidades e parâmetros dos serviços privados complementares dependem de pactuações entre os entes federativos nas instâncias de deliberação do SUS da Lei $n^{\circ} 12.466$, de 24 de agosto de 2011 (BRASIL, 2011).

11. As interdições da Lei $\mathrm{n}^{0} 13.019 / 2014$ (Art. 34), se aplicadas ao regime da complementaridade, poderiam, ainda, causar sérios problemas ao SUS, tendo em vista que $70 \%$ dos municípios contam, muitas vezes, com apenas um serviço privado de saúde que pode complementar a rede SUS (BRASIL, 2014).

12. Por fim, a relação entre o poder público e as organizações sociais na saúde não configura complementaridade na forma prevista no Art. 24 da Lei $\mathrm{n}^{\circ}$ 8.080/1990, mas sim gestão de serviços em regime de parceria.

No mundo contemporâneo, globalizado, tem surgido e se firmado uma consensualidade no desenvolvimento dos serviços públicos e das instituições. O SUS é um paradigma de consenso e cooperação federativa, e também deve sê-lo em suas relações público-privadas, ínsitas à sua organização, onde a negociação-consenso, dotada de maior flexibilidade, deve fundar-se na garantia dos valores das pessoas e nos princípios da administração, garantindo assim a legitimidade e a legalidade contratual.

\section{Referências}

BRASIL. Constituição (1988). Constituição da República Federativa do Brasil. Brasília, DF: Senado Federal: Centro Gráfico, 1988.

. Lei ${ }^{\circ} 11.079$, de 30 de dezembro de 2004.

Institui normas gerais para licitação e contratação de parceria público-privada no âmbito da administração pública. Diário Oficial [da] União. Brasília, DF, $30 \mathrm{dez}$. 2004. Disponível em: <http://www.planalto.gov.br/ccivil_03/_ato2004-2006/2004/lei/l11079.htm>. Acesso em: 21 jul. 2015.

Lei $n^{\circ} 12.466$, de 24 de agosto de 2011. Acrescenta arts. 14-A e 14-B à Lei nº 8.080, de 19 de setembro de 1990. Dispõe sobre as condições para a promoção, proteção e recuperação da saúde, a organização e o funcionamento dos serviços correspondentes e dá outras providências, para dispor sobre as comissões intergestores do Sistema Único de Saúde (SUS), o Conselho Nacional de Secretários de Saúde (CONASS), o Conselho Nacional de Secretarias Municipais de
Saúde (CONASEMS) e suas respectivas composições, e dar outras providências. Diário Oficial [da] União. Brasília, DF, 24 ago. 2011. Disponível em: <http://www. planalto.gov.br/ccivil_03/_Ato2011-2014/2011/Lei/

L12466.htm>. Acesso em: 21 jul. 2015.

. Lei ${ }^{\circ} 13.019$, de 31 de julho de 2014. Estabelece o regime jurídico das parcerias voluntárias, envolvendo ou não transferências de recursos financeiros, entre a administração pública e as organizações da sociedade civil, em regime de mútua cooperação, para a consecução de finalidades de interesse público; define diretrizes para a política de fomento e de colaboração com organizações da sociedade civil; institui o termo de colaboração e o termo de fomento; e altera as Leis nos 8.429, de 02 de junho de 1992, e 9.790, de 23 de março de 1999. Diário Oficial [da] União. Brasília, DF, 31 jul. 2014. Disponível em: <http://www.planalto.gov.br/ccivil_03/_Ato2011-2014/2014/Lei/L13019.htm>. Acesso em: 21 jul. 2015. 
Lei ${ }^{\circ}$ 8.080, de 19 de setembro de 1990. Dispõe sobre as condições para a promoção, proteção e recuperação da saúde, a organização e o funcionamento dos serviços correspondentes e dá outras providências. Diário Oficial [da] União. Brasília, DF, 19 set. 1990. Disponível em: <http://www.planalto.gov.br/ccivil_03/ leis/L8080.htm>. Acesso em: 21 jul. 2015.

Lei $n^{\circ}$ 8.666, de 21de julho de 1993. Regulamenta o art. 37, inciso XXI, da Constituição Federal, institui normas para licitações e contratos da Administração Pública e dá outras providências. Diário Oficial [da] União. Brasília, DF, 21 jul. 1993. Disponível em: <http:// www.planalto.gov.br/CCIVIL_03/leis/L8666cons. htm>. Acesso em: 21 jul. 2015.

Lei $n^{\circ}$ 9.656, de 03 de junho de 1998. Dispõe sobre os planos e seguros privados de assistência à saúde. Diário Oficial [da] União. Brasília, DF, 03 jun. 1998. Disponível em: <http://sistemas.rei.unicamp.br/ pdf/lei-dos-planos-de-saude-lei-n-9-656-de-3-6-1998Attach_s427581.pdf>. Acesso em: 13 ago. 2015.

Supremo Tribunal Federal. Ação direta de inconstitucionalidade. Lei 8.039, de 30 de maio de 1990, que dispõe sobre critérios de reajuste das mensalidades escolares e da outras providencias. Brasília, DF. 1993. Disponível em: <http://redir.stf.jus.br/paginadorpub/ paginador.jsp?doc $\mathrm{TP}=\mathrm{AC} \&$ docID=918>. Acesso em: 13 ago. 2015

FERRAZ, A. A. M. C.; BENJAMIN, A. H. V. O Conceito Constitucional de Relevância Pública. Brasília, DF: OPAS, 1992.

CARVALHO, G.; SANTOS, L. Comentários à Lei Orgânica da Saúde. 4 ed. Campinas: Editora da Unicamp, 2003.

DI PIETRO, M. S. Z. In: CONGRESSO DO TERCEIRO SETOR, 2., 2015. Goiânia: IBDP, 2015.

Parcerias na Administração Pública. 15 ed. São

Paulo: Atlas Editora, 2006.
GRAU, E. R. O Conceito Constitucional de Relevância

Pública. Brasília, DF: OPAS, 1992.

MÂNICA, F. B. O setor privado nos serviços públicos de saúde. Belo Horizonte: Editora Forum, 2010.

MELLO, C. A. B. Curso de Direito Administrativo. $14 \mathrm{ed}$ São Paulo: Malheiros Editores, 2002.

MODESTO, P. O direito administrativo do terceiro setor: a aplicação do direito público às entidades privadas sem fins lucrativos. In: MODESTO, P.; CUNHA JUNIOR, L. A. P. (Coord.). Terceiro Setor e parcerias na área da saúde. São Paulo: IBDP: Editora Forum. 2011.

OLIVEIRA, R. F. Curso de Direito Financeiro. 4 ed. São Paulo: Editora Revista dos Tribunais, 2011.

RODRIGUEZ NETO, E. Saúde: promessas e limites da Constituição. Rio de Janeiro: Editora Fiocruz, 2003.

SANTOS, L. Direito à Saúde e Qualidade de Vida: um mundo de responsabilidades e fazeres. In: (Org.). Direito da Saúde no Brasil. Campinas: Saberes Editora, 2010, 15-62 p.

SÃO PAULO (Estado). Assembleia Legislativa do Estado de São Paulo. Lei Complementar 846, de 04 de junho de 1998. Dispõe sobre a qualificação de entidades como organizações sociais e dá outras providências. Diário Oficial do Estado de São Paulo, 04 jun. 1998. Disponível em: <http://www.al.sp.gov.br/ norma/?id=6680 $>$. Acesso em: 13 ago. 2015.

TORRES, R. L. Curso de Direito Financeiro e Tributário. 18 ed. Rio de Janeiro: Renovar, 2011.

\footnotetext{
Recebido para publicação em junho de 2015

Versão final em julho de 2015

Conflito de interesses: inexistente

Suporte financeiro: não houve
} 